\title{
Push-out Bond Strength of Fiber Posts Cemented Using New Universal Adhesives on Etched and Nonetched Intraradicular Dentin
}

\author{
Valentina Spicciarelli ${ }^{1}$, Hani F Ounsi ${ }^{2}$, Marco Ferrari ${ }^{3}$, Giacomo Corsentino $^{4}$, Crystal Marruganti ${ }^{5}$, Simone Grandini ${ }^{6}$
}

\begin{abstract}
Aim: The aim of this study was to assess if the curing mode and the etching mode could affect the push-out bond strength of different post cementation systems using two universal adhesives.

Materials and methods: A total of 100 single-rooted teeth were divided into Prime \& Bond Elect (PBE), Prime \& Bond Active (PBA), and Prime \& Bond XP (PBXP) as a control. The PBE, PBA, and PBXP were used in the self-etch (SE) and etch and rinse (E\&R) mode. Post cementation was performed using Core X flow used in dark-cure and in light-cure. Data were analyzed using the one-way ANOVA test and post hoc Bonferroni and Dunnet tests. The Student's $t$ test was performed to find significance between two independent groups.

Results: Bond strength was significantly influenced by the adhesive strategies. The PBE and PBA obtained higher values when used in the SE mode $(p<0.001)$. Light-cured groups obtained significantly higher values $(p<0.001)$ compared to dark-cured groups. The post space region also had a significant effect on the bond strength; the apical third recorded lower values in all groups $(p<0.001)$.

Conclusion: The PBA and PBE universal adhesives obtained higher PBS values when used in the SE mode and followed by the light-curing of resin cement.

Clinical significance: Universal adhesives represent a good alternative to the conventional total-etch adhesive system for fiber post cementation. Since they perform better in SE, they would be recommendable in clinical practice, as they can be used with a simplified technique.

Keywords: Bond strength, Dark-curing, Fiber post, Laboratory research, Universal adhesives.

The Journal of Contemporary Dental Practice (2020): 10.5005/jp-journals-10024-2750
\end{abstract}

\section{INTRODUCTION}

The most common complication of endodontically treated teeth restored with fiber posts is debonding of these posts from dentin. ${ }^{1,2}$ Bonding to root canals might prove difficult and is related to the handling characteristics of the adhesive system, root anatomy, tooth position, presence or absence of coronal residual tissue, the curing technique, and experience and skill of the operators.

Bonding between adhesives and post, and between adhesives and dentin, may be improved through different post surface treatments and careful choice of root canal irrigants, adhesives, and resin cements. ${ }^{3}$

One of the most recent novelties, in adhesive dentistry, is the introduction of universal adhesives. They combine the already existing "all-in-one" concept with the versatility of being adaptable to multiple clinical situations. ${ }^{4}$ An adhesive that can be applied in the SE and E\&R mode allows the practitioner to decide on a specific adhesive protocol that is most suited for the cavity shape. ${ }^{5}$ Although relatively new, the literature provides information on the performance of these adhesive systems on both enamel ${ }^{6-8}$ and coronal dentin; ${ }^{9-13}$ there is however little information regarding their bond strength to root canal dentin.

In this study, the performances of a conventional total etch two-steps adhesive were compared to those of two new universal adhesives used in the SE and E\&R mode to intraradicular dentin.

The aim of this study was to compare the in vitro performances of different dark-cured post cementation systems with the lightcured conventional post cementation system, with and without prior etching.
${ }_{1,4-6}$ Department of Restorative Dentistry and Endodontics, Graduate
School of Dental Medicine, University of Siena, Siena, Italy
${ }^{2}$ Department of Restorative Dentistry and Endodontics, Faculty of
Dental Medicine, Lebanese University, Beirut, Lebanon; Tuscan School
of Dentistry, University of Siena, Siena, Italy
${ }^{3}$ Department of Prosthodontics, Graduate School of Dental Medicine,
University of Siena, Siena, Italy Corresponding Author: Valentina Spicciarelli, Department of Restorative Dentistry and Endodontics, Graduate School of Dental Medicine, University of Siena, Siena, Italy, Phone: +39 3200343081, e-mail: valentina.spicciarelli@gmail.com

How to cite this article: Spicciarelli V, Ounsi HF, Ferrari M, et al. Pushout Bond Strength of Fiber Posts Cemented Using New Universal Adhesives on Etched and Nonetched Intraradicular Dentin. J Contemp Dent Pract 2020;21(1):91-96.

Source of support: Nil

Conflict of interest: None

The null hypothesis tested was that the push-out bond strength of root canal fiber posts was not significantly affected by the curing technique, the adhesive system, or the root region.

\section{Materials and Methods}

\section{Tooth Collection and Selection}

A total of 100 recently extracted single-rooted human teeth of similar size and shape were selected for this study. Preoperative radiographs were taken in buccolingual and proximal directions,

(c) The Author(s). 2020 Open Access This article is distributed under the terms of the Creative Commons Attribution 4.0 International License (https://creativecommons. org/licenses/by-nc/4.0/), which permits unrestricted use, distribution, and non-commercial reproduction in any medium, provided you give appropriate credit to the original author(s) and the source, provide a link to the Creative Commons license, and indicate if changes were made. The Creative Commons Public Domain Dedication waiver (http://creativecommons.org/publicdomain/zero/1.0/) applies to the data made available in this article, unless otherwise stated. 
using periapical films to confirm the presence of a single canal and absence of calcifications or resorptions. Only teeth with straight root canal, mature root apices, no caries, or previous restorative and endodontic treatments were included in the study. The root surfaces had been cleaned with periodontal curettes (Hu-Friedy, Chicago, IL, USA) and an ultrasonic scaler (EMS, Nyon, Switzerland). A 4.5× stereomicroscope (Nikon SMZ645, Tokyo, Japan) was employed to rule out any external radicular cracks. Teeth were decoronated to create a standard access to the root canal and the root portion at least $14 \mathrm{~mm}$ long, using a low-speed saw (Isomet, Buehler, Lake Buff, IL, USA) under water cooling. Each root canal was checked for patency using a size $10 \mathrm{~K}$-file (FlexOFiles; DENTSPLY Sirona, Ballaigues, Switzerland) until the file was seen at the apical foramen. Teeth were stored for no longer than 1 month in distilled water until use to prevent dehydration.

\section{Samples Preparation}

All samples were prepared by the same operator using R25 (Reciproc, DENTSPLY-VDW, Munich, Germany) to the working length. Instruments were used in reciprocating motion with an endodontic micromotor (VDW Silver) using RECIPROC ALL as setting. After the use of each instrument, canals were irrigated with $2 \mathrm{~mL}$ of $5.25 \% \mathrm{NaOCl}$. After completing the instrumentation, $10 \mathrm{~mL}$ of $17 \%$ EDTA (Produits Dentaires SA, Vevey, Switzerland) was placed into the canals and left for 2 minutes (under a constant speed of 5 $\mathrm{mL} /$ minute). Finally root canals were flushed using $10 \mathrm{~mL}$ of $5.25 \%$ $\mathrm{NaOCl}$ followed by $3 \mathrm{~mL}$ of distilled water. Then canals were dried with paper points.

Root canals were then filled with gutta-percha cones and $\mathrm{AH}$ Plus Root Canal Sealer (Dentsply DeTrey, Konstanz, Germany) using the continuous condensation wave technique, cutting the guttapercha cone to $4 \mathrm{~mm}$ from the apex (BeeFill 2in1, VDW). Hand pluggers were then used to further compact the gutta-percha.

After 24 hours, the post space was prepared under water irrigation using precision drills. To preserve the apical seal, at least $3 \mathrm{~mm}$ of the root filling was retained at the apical level. Canals were then dried with paper points.

Samples were randomly divided into nine test groups and a control group ( $n=10$ ) (Table 1) according to the adhesive system used and the polymerization mode.

Etching was performed (+) for groups $0, \mathrm{I}, \mathrm{II}, \mathrm{III}, \mathrm{VI}$, and VII, while the SE groups (-) were IV, V, VIII, and IX; light curing of resin cement was performed (+) for groups 0 , II, IV, VI, and VIII, while the dark-cure groups were I, III, V, VII, and IX.

The materials used for this study were Prime \& Bond XP (PBXP) (Dentsply DeTrey), Prime \& Bond Active (PBA) (Dentsply DeTrey), and Prime \& Bond Elect (PBE) (Dentsply DeTrey); for all the groups, $X$-Post (Dentsply DeTrey) No 3 and Core-X flow (Dentsply DeTrey) were used.

In groups where etching was required, it was performed with DeTrey Conditioner (DENTSPLY Sirona, UK) for 15 seconds, rinsed for 15 seconds and dried with paper points. One to two drops of adhesive were mixed with an equal number of drops of Self-Cure Activator (Dentsply Caulk, Milford, DE, USA) for 2 seconds with a clean brush tip. Adhesive was applied to cavity surfaces, left undisturbed for 20 seconds. Paper points were used to remove surplus from the canal and adhesive mix was gently dried for 5 seconds with a moderate air flow from an air-water syringe. The adhesive mixed with Self-Cure Activator was applied to the post and then dried with air. Core-X flow was immediately placed onto the post surface and to the orifice of the post hole preparation and stabilized within 40 seconds. In groups where light curing was required, it was performed for 20 seconds with an irradiance of $600 \mathrm{~mW} / \mathrm{cm}^{2}$. Dark curing was performed for 24 hours at $37^{\circ}$ and $100 \%$ humidity.

\section{Push-out Test}

The roots were horizontally sectioned into six slices of $1 \pm 0.1 \mathrm{~mm}$ thickness by using a low-speed saw (Isomet) under water coolant. Each two slices represented one of the root thirds: cervical, middle, and apical. The first slice of $1 \mathrm{~mm}$ in thickness was discarded to avoid imperfections on the adhesive interface especially caused by the oxygen presence.

The exact thickness of each slice was measured with a digital caliper (Orteam s.r.l., Milan, Italy) to an accuracy of $0.01 \mathrm{~mm}$. The diameter and perimeter of the canal, in both sides of the slice, were measured for calculation of the adhesive area by using the following formula to calculate the area for the frustum of a cone:

$$
A=\pi(R+r) \sqrt{h^{2}+(R-r)^{2}}
$$

where $\pi$ is constant, $R$ is the larger radius, $r$ is the lower radius, and $h$ is the thickness of the dental slice. The push-out test was performed using a universal testing machine (Triax Digital 50, Controls, Milan, Italy) at a crosshead speed of $0.5 \mathrm{~mm} / \mathrm{minute}$. Each specimen was carefully positioned over a rigid basis, with the apical face facing the punch tip. The push-out pin was carefully placed at the center of the post surface. The push-out bond strength of each specimen (MPa) was calculated as the force $(\mathrm{N})$ of failure divided by the adhesive area $\left(\mathrm{mm}^{2}\right)$.

After the push-out test, the slices were analyzed with a stereomicroscope (Nikon SMZ645, Tokyo, Japan) to verify the failure

Table 1: All test groups (I-IX) and the control group (0)

\begin{tabular}{|c|c|c|c|c|c|}
\hline Group & Etching & Adhesive & $\begin{array}{l}\text { Light curing of } \\
\text { adhesive }\end{array}$ & Resin cement & $\begin{array}{l}\text { Light curing of resin } \\
\text { cement }\end{array}$ \\
\hline 0 (control) & + & PBXP & - & Core-X Flow & + \\
\hline I & + & PBXP & - & Core-X Flow & - \\
\hline II & + & PBA & - & Core-X Flow & + \\
\hline III & + & PBA & - & Core-X Flow & - \\
\hline IV & - & PBA & - & Core-X Flow & + \\
\hline V & - & PBA & - & Core-X Flow & - \\
\hline VI & + & PBE & - & Core-X Flow & + \\
\hline VII & + & PBE & - & Core-X Flow & - \\
\hline VIII & - & PBE & - & Core-X Flow & + \\
\hline IX & - & PBE & - & Core-X Flow & - \\
\hline
\end{tabular}


mode, which was divided as follows: adhesive failure between the dentin and cement (AD), adhesive failure between the post and cement (AP), mixed failure (M), or cohesive failure in the post (C).

\section{Statistical Analysis}

Quantitative variables were expressed as mean (standard deviation) and confidence interval (95\%). Normality distribution of data was proved according to the Shapiro-Wilk test, then the ANOVA test was used to detect the significance between more than two independent groups, and, in case of significance, the post hoc test of Bonferroni or Dunnet was done. Student's $t$ test was performed to find significant differences between two independent groups. The homogeneity of variances was carried out by the Levene's test and in the case of heteroscedasticity the Welch statistics were used. All analyses were performed using the SPSS software (v.20), and $p$ values $\leq 0.05$ were considered to be statistically significant in all tests.

\section{Results}

The results of the push-out bond strength (PBS) test for fiber posts bonded to intraradicular dentin using universal adhesives in different etching and curing modes are shown in Table 2.

The one-way ANOVA test and the post hoc Dunnet test revealed significant differences between groups I, III, IV, VII, VIII, IX, and control group $(p<0.001)$.

As evidenced by mean values and related confidence intervals, the highest PBS values were detected for groups VIII, IV, and IX (in descending order), and the lowest values were for groups I, III, and VII. No statistically significant differences were found between groups II, V, and VI and the control group.

The Bonferroni post hoc test for multiple comparisons revealed statistically significant differences between the adhesives and in particular between PBXP and PBE, recording higher values for the second one (Table 3 and Fig. 1).

Statistical analysis was also conducted within groups of the same adhesive system. For PBA test groups, statistically significant

Table 2: Distribution of PBS values in all groups (mean, $\mathrm{SD}, \mathrm{Cl}_{95 \%}$ )

\begin{tabular}{lllc}
\hline Group & Mean $(S D)$ & $C_{95 \%}$ & $p$ value* \\
\hline Control & $10.30(0.27)$ & $10.10,10.49$ & \\
Test 1 & $9.61^{*}(0.30)$ & $9.39,9.82$ & $<0.001$ \\
Test 2 & $10.52(0.31)$ & $10.30,10.75$ & 0.286 \\
Test 3 & $9.68^{*}(0.30)$ & $9.47,9.89$ & $<0.001$ \\
Test 4 & $10.79^{*}(0.28)$ & $10.58,10.99$ & 0.001 \\
Test 5 & $10.06(0.18)$ & $9.93,10.19$ & 0.245 \\
Test 6 & $10.29(0.19)$ & $10.16,10.42$ & 1.00 \\
Test 7 & $9.85^{*}(0.29)$ & $9.64,10.06$ & 0.002 \\
Test 8 & $10.89^{*}(0.19)$ & $10.76,11.03$ & $<0.001$ \\
Test 9 & $10.74^{*}(0.25)$ & $10.56,10.92$ & 0.002 \\
\hline * 0.05 & & &
\end{tabular}

${ }^{*} p<0.05$

Table 3: PBS values between the adhesives (mean, SD, $\mathrm{Cl}_{95 \%}$ )

\begin{tabular}{lll}
\hline Groups & Mean (SD) & $\mathrm{Cl}_{95 \%}$ \\
\hline PBXP & ${ }^{\mathrm{a}} 9.95(0.45)$ & $9.74,10.16$ \\
PBA & $10.26(0.54)$ & $10.10,10.42$ \\
PBE & ${ }^{\mathrm{a}} 10.44(0.47)$ & $10.29,10.59$ \\
\hline
\end{tabular}

${ }^{a} p<0.05$, Bonferroni test (same letter indicates significance between two groups) differences were found $(p<0.001)$ between groups II and III, II and V, III and IV, III and V, and IV and V, respectively (Table 4).

For PBE test groups, statistically significant differences were found ( $p<0.001$ ) between groups VI and VII, VI and VIII, VI and IX, VII and VIII, and VII and IX, respectively (Table 5).

Table 6 indicates values obtained from the comparison between PBA and PBE test groups with the same parameters.

As shown in Table 2, statistically significant differences were observed only between groups $\mathrm{V}$ and IX, recording significantly higher values for group IX $(p<0.001)$.

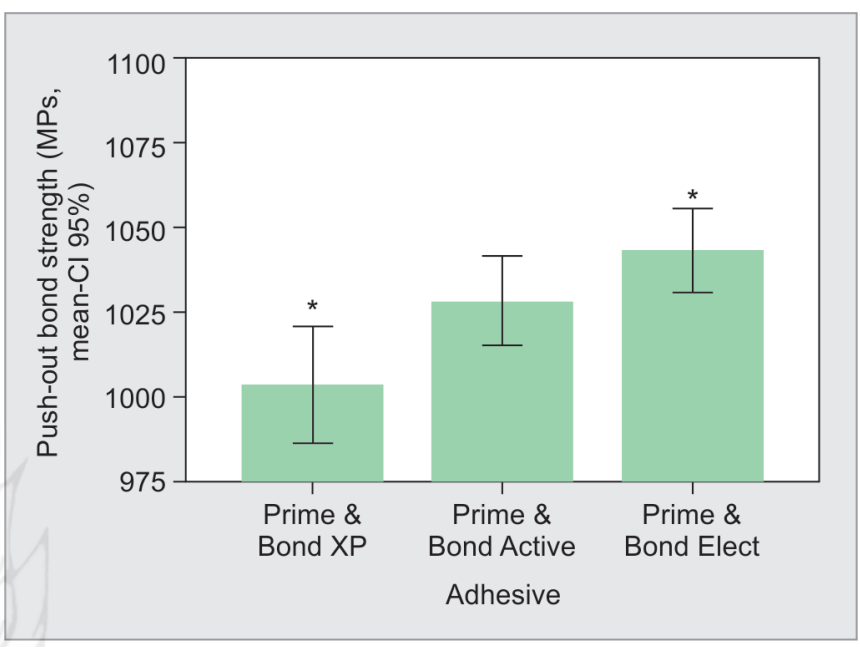

Fig. 1: Distribution of PBS values (mean, $\mathrm{Cl}_{95 \%}$ ). Each column indicates an adhesive system. ${ }^{*} p<0.05$, Bonferroni's test

Table 4: PBS values for Prime \& Bond Active test groups (mean, $\mathrm{SD}, \mathrm{Cl}_{95 \%}$ )

\begin{tabular}{lll}
\hline Group & Mean $(S D)$ & $C l_{95 \%}$ \\
\hline Test 2 & ${ }^{\mathrm{a}, \mathrm{b}} 10.52(0.31)$ & $10.30,10.75$ \\
Test 3 & ${ }^{\mathrm{a}, \mathrm{c}, \mathrm{d}} 9.68(0.30)$ & $9.47,9.89$ \\
Test 4 & ${ }^{\mathrm{c}, \mathrm{e}} 10.79(0.28)$ & $10.58,10.99$ \\
Test 5 & $\mathrm{b}^{\mathrm{b}, \mathrm{d}, \mathrm{e}} 10.06(0.18)$ & $9.93,10.19$ \\
\hline
\end{tabular}

${ }^{a-e} p<0.05$, Bonferroni's test (same letters indicate significance between two groups)

Table 5: PBS values for Prime \& Bond Elect test groups (mean, SD, $\mathrm{Cl}_{95 \%}$ )

\begin{tabular}{|c|c|c|}
\hline Group & Mean (SD) & $\mathrm{Cl}_{95 \%}$ \\
\hline Test 6 & $a, b, c 10.29(0.19)$ & $10.16,10.42$ \\
\hline Test 7 & $\mathrm{a}, \mathrm{d}, \mathrm{e} 9.85(0.29)$ & $9.64,10.06$ \\
\hline Test 8 & b,d $10.89(0.19)$ & $10.76,11.03$ \\
\hline Test 9 & c,e $10.74(0.25)$ & $10.56,10.92$ \\
\hline
\end{tabular}

${ }^{a-e} p<0.05$, Bonferroni's test (same letters indicate significance between two groups)

Table 6: PBS values for couple of groups with same parameters but different adhesive systems (mean, $\mathrm{SD}, \mathrm{Cl}_{95 \%}$ )

\begin{tabular}{lc}
\hline Test & $p$ \\
\hline $2-6$ & 0.06 \\
$3-7$ & 0.21 \\
$4-8$ & 0.33 \\
$5-9$ & $<0.001$ \\
\hline
\end{tabular}


The Student's $t$ test for independent groups revealed statistically significant differences between light-cured groups and dark-cured groups ( $p<0.001)$, recording significantly higher values for light-cured groups (Table 7).

Significantly differences were found also between SE groups and E\&R groups ( $p<0.001)$; in particular, SE groups obtained significantly higher values (Table 8 ).

Statistical analysis was conducted also between the groups for root levels. The Bonferroni's test for multiple comparisons showed statistically significant differences between the coronal and apical section and the middle and apical section in all groups.

By making a comparison for each type of section between the groups, statistically significant differences were observed only for the apical section $(p<0.001)$; the Dunnet's test revealed statistically significant differences between apical section values of the control group and test groups I, III, IV, VII, VIII, and IX ( $p<0.001)$, recording lower values for groups I, III, and VII. All values are showed in Table 9.

Fracture occurred mainly due to adhesive failure between the dentin and cement (76.5\%) and mixed failure (18.7\%), minimally due to adhesive failure between the post and cement (4.8\%).

\section{Discussion}

A hypothetical model was used to investigate the effects of root level, adhesive systems, and different curing modes on the bond strength of posts inside the canal.

The groups showing the best PBS values were VIII, IV, and IX and the ones obtaining the worst values were groups I, III, and VII. Prime \& Bond Elect universal adhesive obtained higher PBS values than the PBXP adhesive system. Differences were observed

Table 7: PBS values for light-cured and dark-cured groups (mean, SD, $\left.\mathrm{Cl}_{95 \%}\right)$

\begin{tabular}{lll}
\hline Group & Mean (SD) & $\mathrm{Cl}_{95 \%}$ \\
\hline Light curing - & $9.99(0.49)$ & $9.85,10.13$ \\
Light curing + & $10.56(0.35)$ & $10.46,10.66$ \\
\hline
\end{tabular}

Table 8: PBS values for etched and nonetched groups (mean, SD, $\mathrm{Cl}_{95 \%}$ )

\begin{tabular}{lll}
\hline Group & Mean (SD) & $\mathrm{Cl}_{95 \%}$ \\
\hline Etching + & $9.99(0.45)$ & $9.86,10.12$ \\
Etching - & $10.62(0.40)$ & $10.49,10.75$ \\
\hline
\end{tabular}

between light-cured groups and dark-cured groups, and between E\&R groups and SE groups, recording higher values for light-cured groups and SE groups, respectively.

Coronal third obtained higher PBS values than middle and apical thirds. Groups I, III, and VII obtained statistically lower values for the apical section compared to the other groups.

The failure mode was due to adhesion between resin cement and root dentin in $76.5 \%$ of cases.

The null hypothesis was rejected because the bond strength of the fiberglass post was affected by root level, etching mode, adhesive system, and polymerization mode of resin cement.

The literature describes a variety of experimental tests for the evaluation of the bond strength between root canal dentine and fiber posts, such as the pull-out test, ${ }^{14}$ the microtensile test, ${ }^{15}$ and the push-out test. ${ }^{16,17}$ In the present study, the push-out test was performed using 1-mm-thick tooth slices, because this approach offers the advantage of smaller adhesive areas avoiding the difficulties of the microtensile specimen preparation. ${ }^{18,19}$ This technique has been indicated as a significant experimental tool for the evaluation of mechanical properties of adhesive interfaces. ${ }^{20}$

Many aspects can impact the quality of the post-space adhesive interface, such as products resulting from endodontic treatment before post cementation, ${ }^{21,22}$ adhesive manipulation, canal anatomy, and dentin morphology. ${ }^{23}$ Cervical radicular dentin is morphologically similar to deep coronal dentin, ${ }^{24}$ but apical radicular dentin presents important differences: dentin tubules gradually decrease toward the root apex in number and diameter; ${ }^{25}$ this may result in a decreased adhesive infiltration of canal apical portion. ${ }^{26}$

In accordance with previous studies, ${ }^{27-29}$ a lower bond strength of resin cement in the apical third of the root was observed in this experimentation.

The in vitro literature suggests that bond strength is improved by the use of multimode adhesives with prior acid etching only for enamel; this effect was not evident for dentin with the use of mild universal adhesives. ${ }^{30}$ Self-etch and universal adhesives have a less acidic composition compared with phosphoric acid, thus the reduced potential to demineralize the full-mineral phase of enamel and consequently to create appropriate micro-retentive porosities. ${ }^{31}$ On the other hand, a 1-year in vitro study of adhesive stability over time for a multimode adhesive applied using SE and E\&R procedures claimed improved effectiveness to middle and deep coronal dentin when the universal adhesive was used in the

Table 9: PBS values between sections in columns and groups in rows (mean, $\mathrm{SD}, \mathrm{Cl}_{95 \%}$ )

\begin{tabular}{|c|c|c|c|c|c|c|c|}
\hline \multirow[b]{2}{*}{ Group } & \multicolumn{2}{|c|}{ Coronal } & \multicolumn{2}{|c|}{ Middle } & \multicolumn{2}{|c|}{ Apical } & \multirow[b]{2}{*}{$p$ value } \\
\hline & Mean (SD) & $\mathrm{Cl}_{95 \%}$ & Mean (SD) & $\mathrm{Cl}_{95 \%}$ & Mean (SD) & $\mathrm{Cl}_{95 \%}$ & \\
\hline Control & $12.06(0.46)^{a}$ & $11.73,12.39$ & $11.60(0.49)^{b}$ & $11.25,11.95$ & $7.23(0.61)^{a, b}$ & $6.79,7.67$ & $<0.001$ \\
\hline Test 1 & $12.06(0.50)^{\mathrm{a}}$ & $11.71,12.42$ & $11.51(0.53)^{b}$ & $11.13,11.89$ & $5.25(0.45)^{a, b, *}$ & $4.92,5.57$ & $<0.001$ \\
\hline Test 2 & $12.19(0.48)^{a}$ & $11.84,12.54$ & $11.76(0.59)^{b}$ & $11.33,12.18$ & $7.63(0.22)^{a, b}$ & $7.47,7.78$ & $<0.001$ \\
\hline Test 3 & $11.78(0.41)^{\mathrm{a}}$ & $11.49,12.07$ & $11.56(0.44)^{b}$ & $11.25,11.88$ & $5.69(0.56)^{a, b, *}$ & $5.29,6.09$ & $<0.001$ \\
\hline Test 4 & $12.04(0.29)^{a}$ & $11.83,12.25$ & $11.61(0.34)^{b}$ & $11.36,11.85$ & $8.71(0.56)^{a, b, *}$ & $8.31,9.11$ & $<0.001$ \\
\hline Test 5 & $11.97(0.51)^{\mathrm{a}}$ & $11.61,12.34$ & $11.54(0.33)^{\mathrm{b}}$ & $11.30,11.78$ & $6.67(0.24)^{a, b}$ & $6.50,6.84$ & $<0.001$ \\
\hline Test 6 & $11.98(0.52)^{\mathrm{a}}$ & $10.60,12.35$ & $11.64(0.34)^{b}$ & $11.40,11.89$ & $7.24(0.36)^{a, b}$ & $6.99,7.50$ & $<0.001$ \\
\hline Test 7 & $12.00(0.53)^{a}$ & $11.62,12.38$ & $11.69(0.51)^{b}$ & $11.33,12.05$ & $5.87(0.51)^{\mathrm{a}, \mathrm{b}, *}$ & $5.50,6.24$ & $<0.001$ \\
\hline Test 8 & $11.98(0.31)^{\mathrm{a}}$ & $11.76,12.20$ & $11.99(0.27)^{\mathrm{b}}$ & $11.80,12.18$ & $8.72(0.33)^{a, b, *}$ & $8.48,8.96$ & $<0.001$ \\
\hline Test 9 & $12.15(0.48)^{a}$ & $11.80,12.49$ & $11.83(0.40)^{\mathrm{b}}$ & $11.54,12.12$ & $8.25(0.29)^{a, b, *}$ & $8.04,8.46$ & $<0.001$ \\
\hline
\end{tabular}

$\mathrm{a}, \mathrm{b} p<0.05$, Bonferroni's test (same letters indicate significance between two groups)

${ }^{*} p<0.05$ Dunnet's test (test $\mathrm{i}_{\mathrm{i}}$ vs control group) 
SE mode. ${ }^{32}$ Considering that the universal adhesives evaluated (PBA, PBE) are classified as mild adhesive systems, they demonstrated no differences in the middle and coronal intraradicular dentin bond strength between the E\&R and SE approaches, regardless of the curing mode of resin cement. The only differences were found for the apical third of post space, where both universal adhesives tested obtained higher bond strength values when used in the SE mode; this may be due to the fact that etchants may not flow completely in the root canal, causing inadequate exposure of the collagen fibers. Furthermore, etchants cannot be removed completely, and residual etchants may cause low-pH-related inhibition of polymerization of resin-based materials. ${ }^{33}$ The depth of the post space preparation can also affect the application and evaporation of the adhesive system, and residual water and/or solvent may compromise the performance of adhesives. ${ }^{34}$ Moreover, the inclusion of multiple steps increases technique sensitivity. ${ }^{35}$

Nonetheless, some authors have found no significant differences in the bond strength in different parts of the root canal. ${ }^{36,37}$

Another aspect that can influence the bond strength is the depth of light penetration. During the cementation of fiber posts, the curing light is severely attenuated by the post before it reaches the resin cement. ${ }^{38,39}$ Although no statistically significant differences were found between resin cement bond strength values in dark cure and light cure in the coronal and middle third of the post space, better values were recorded for the apical thirds of test groups using the light-curing mode compared to the apical thirds of the same groups using the self-curing mode. This agrees with previous studies evaluating the hardness of dual-cured resin cements, ${ }^{39,40}$ which have shown that the self-curing of such products is less effective than the dual curing.

The light-polymerization technique can also influence the bond strength: in this study, the soft-start polymerization technique ${ }^{41}$ was preferred to the single-step polymerization technique, this last technique seemed to be related to a reduction in hybrid layer formation ${ }^{42}$ and to a higher risk of adhesive link interruption at the interface level. ${ }^{43}$

The failure mode analysis showed that the weakest link in the cementation of fiber posts to the canal with resin cement is the bonding to dentin. Only a few adhesive failures between the cement and the post were observed. These results agree with those of other studies. ${ }^{44,45}$

Future in vitro studies are required to analyze the performance of universal adhesives to root canal dentin. Additionally, in vivo tests are needed to assess the long-term clinical behavior of these new simplified adhesives.

\section{Conclusion}

According to this in vitro study PBA and PBE universal adhesives used in the SE mode represent a better alternative to the totaletch adhesive system for glass fiber post cementation, especially when followed by the light curing of resin cement. Materials and techniques that facilitate the substrate preparation and polymerization of resin cements along root canal are recommended to minimize failures.

\section{Clinical Significances}

Universal adhesive represent a good alternative to conventional the total-etch adhesive system for fiber post cementation. Since they perform better in SE, they would be recommendable in clinical practice, as they can be used with a simplified technique.

\section{Ethical Approval}

This article does not contain any studies with human participants or animals performed by any of the authors.

\section{Authors Contribution}

Valentina Spicciarelli participated in the experimental design, performed the experiments, performed statistical analysis, and wrote the manuscript. Hani F Ounsi participated in the experimental design, contributed substantially to introduction, and proofread the manuscript. Marco Ferrari participated in the experimental design and supported the experiments. Giacomo Corsentino participated in the experimental design, performed the experiments, performed statistical analysis, and wrote the manuscript. Crystal Marruganti participated in the experimental design and proofread the manuscript. Simone Grandini participated in the experimental design, supported the experiments, and proofread the manuscript.

\section{References}

1. Ferrari M, Cagidiaco MC, Goracci C, et al. Long-term retrospective study of the clinical performance of fiber posts. Am J Dent 2007;20(5):287-291.

2. RasimickBJ, Wan J, Musikant BL, et al. A review of failure modes in teeth restored with adhesively luted endodontic dowels. J Prosthodont 2010;19(8):639-646. DOI: 10.1111/j.1532-849X.2010.00647.x.

3. Maroulakos G, He J, Nagy WW. The Post-endodontic adhesive interface: Theoretical perspectives and potential flaws. J Endod 2018;44(3):363-371. DOI: 10.1016/j.joen.2017.11.007.Epub.

4. Wagner A, Wendler M, Petschelt A, et al. Bonding performance of universal adhesives in different etching modes. J Dent 2014;42(7): 800-807. DOI: 10.1016/j.jdent.2014.04.012.

5. Hanabusa M, Mine A, Kuboki T, et al. Bonding effectiveness of a new 'multi-mode' adhesive to enamel and dentine. J Dent 2012;40(6): 475-484. DOI: 10.1016/j.jdent.2012.02.012.

6. Lawson NC, Robles A, Fu CC, et al. Two-year clinical trial of a universal adhesive in total-etch and self-etch mode in non-carious cervical lesions. J Dent 2015 Oct;43(10):1229-1234. DOI: 10.1016/ j.jdent.2015.07.009.

7. Diniz AC, Bandeca MC, Pinheiro LM, et al. Influence of different etching modes on bond strength to enamel using universal adhesive systems. J Contemp Dent Pract 2016;17(10):820-825. DOI: 10.5005/ jp-journals-10024-1937.

8. Suzuki T, Takamizawa T, Barkmeier WW, et al. Influence of etching mode on enamel bond durability of universal adhesive systems. Oper Dent 2016;41(5):520-530. DOI: 10.2341/15-347-L.

9. Tsujimoto A, Barkmeier WW, Hosoya Y, et al. Comparison of enamel bond fatigue durability of universal adhesives and two-step self-etch adhesives in self-etch mode. Am J Dent 2017;30(5):279-284.

10. Chen $\mathrm{C}, \mathrm{Niu} \mathrm{LN}, \mathrm{Xie} \mathrm{H}$, et al. Bonding of universal adhesives to dentine. Old wine in new bottles? J Dent 2015;43(5):525-536. DOI: 10.1016/ j.jdent.2015.03.004.

11. Grégoire G, Sharrock P, Prigent Y. Performance of a universal adhesive on etched and non-etched surfaces: Do the results match the expectations? Mater Sci Eng C Mater Bio Appl 2016;66:199-205. DOI: 10.1016/j.msec.2016.04.022.

12. Jayasheel A, Niranjan N, Pamidi H, et al. Comparative evaluation of shear bond strength of universal dental adhesives - An in vitro study. J Clin Exp Dent 2017;9(7):e892-e896. DOI: 10.4317/jced.53816.

13. Forgerini TV, Ribeiro JF, Rocha RO, et al. Role of etching mode on bonding longevity of a universal adhesive to eroded dentin. J Adhes Dent 2017;19(1):69-75. DOI: 10.3290/j.jad.a37723. 
14. De Santis R, Prisco D, Apicella A, et al. Carbon fiber post adhesion to resin luting cement in the restoration of endodontically treated teeth. J Mater Sci Mater Med 2000;11(4):201-206. DOI: 10.1023/A:1008987823354.

15. Vano M, Cury AH, Goracci $C$, et al. Retention of fiber posts cemented at different time intervals in canals obturated using an epoxy resin sealer. J Dent 2008;36(10):801-807. DOI: 10.1016/j.jdent.2008.05.016.

16. Gurgel-Filho ED, Lima FC, Saboia Vde P, et al. Push-out bond strength of a self-adhesive resin cement used as endodontic sealer. Restor Dent Endod 2014 Nov;39(4):282-287. DOI: 10.5395/rde.2014.39.4.282.

17. Kadam A, Pujar M, Patil C. Evaluation of push-out bond strength of two fiber-reinforced composite posts systems using two luting cements in vitro. J Conserv Dent 2013;16(5):444-448. DOI: 10.4103/0972-0707.117522.

18. Goracci C, Sadek FT, Fabianelli A, et al. Evaluation of the adhesion of fiber posts to intraradicular dentin. Oper Dent 2005;30(5):627-635.

19. Bouillaguet $S$, Schütt $A$, Alander $P$, et al. Hydrothermal and mechanical stresses degrade fiber-matrix interfacial bond strength in dental fiber-reinforced composites. J Biomed Mater Res B Appl Biomater 2006;76(1):98-105. DOI: 10.1002/jbm.b.30349.

20. Coniglio I, Magni E, Cantoro A, et al. Push-out bond strength of circular and oval-shaped fiber posts. Clin Oral Investig 2011;15(5):667-672. DOI: 10.1007/s00784-010-0448-0.

21. Serafino C, Gallina G, Cumbo E, et al. Surface debris of canal walls after post space preparation in endodontically treated teeth: A scanning electron microscopic study. Oral Surg Oral Med Oral Pathol Oral Radiol Endod 2004;97(3):381-387. DOI: 10.1016/j.tripleo.2003. 10.004.

22. Muniz L, Mathias P. The influence of sodium hypochlorite and root canal sealers on post retention in different dentin regions. Oper Dent 2005;30(4):533-539.

23. Camargo $\mathrm{CH}$, Siviero $\mathrm{M}$, Camargo SE, et al. Topographical, diametral, and quantitative analysis of dentin tubules in the root canals of human and bovine teeth. J Endod 2007;33(4):422-426. DOI: 10.1016/j. joen.2006.12.011.

24. Caiado AC, de Goes MF, de Souza-Filho FJ, et al. The effect of acid etchant type and dentin location on tubular density and dimension. J Prosthet Dent 2010;103(6):352-361. DOI: 10.1016/S00223913(10)60076-5.

25. Pashley DH, Ciucchi B, Sano $\mathrm{H}$, et al. Bond strength versus dentine structure: a modelling approach. Arch Oral Biol 1995;40(12):1109-1118. DOI: 10.1016/0003-9969(95)00090-9.

26. Manicardi CA, Versiani MA, Saquy $P C$, et al. Influence of filling materials on the bonding interface of thin-walled roots reinforced with resin and quartz fiber posts. J Endod 2011;37(4):531-537. DOI: 10.1016/j.joen.2010.12.009.

27. Luque-Martinez IV, Perdigão J, Muñoz MA, et al. Effects of solvent evaporation time on immediate adhesive properties of universal adhesives to dentin. Dent Mater 2014;30(10):1126-1135. DOI: 10.1016/ j.dental.2014.07.002.

28. Montanari M, Prati C, Piana G. Differential hydrolytic degradation of dentin bonds when luting carbon fiber posts to the root canal. Med Oral Patol Oral Cir Bucal 2011;16(3):e411-e417. DOI: 10.4317/ medoral.16.e411.
29. Calixto LR, Bandeca MC, Clavijo V, et al. Effect of resin cement system and root region on the push-out bond strength of a translucent fiber post. Oper Dent 2012;37(1):80-86. DOI: 10.2341/11-035-L.

30. Rosa WL, Piva E, Silva AF. Bond strength of Universal adhesives: a systematic review and meta-analysis. J Dent 2015;43(7):765-776. DOI: 10.1016/j.jdent.2015.04.003.

31. Pashley DH, Tay FR, Breschi L, et al. State of the art etchand-rinse adhesives. Dent Mater 2011;27(1):1-16. DOI: 10.1016/ j.dental.2010.10.016.

32. Marchesi G, Frassetto A, Mazzoni A, et al. Adhesive performance of a multi-mode adhesive system: 1-year in vitro study. J Dent 2014;42(5):603-612. DOI: 10.1016/j.jdent.2013.12.008.

33. Monticelli F, Osorio R, Mazzitelli C, et al. Limited decalcification/ diffusion of self adhesive cements into dentin. J Dent Res 2008;87(10):974-979. DOI: 10.1177/154405910808701012.

34. Soares CJ, Pereira JC, Valdivia ADCM, et al. Influence of resin cement and post configuration on bond strength to root dentine. Int Endod J 2012;45(2):136-145. DOI: 10.1111/j.1365-2591.2011.01953.x.

35. Gomes GM, Gomes OM, Reis A, et al. Effect of operator experience on the outcome of fiber post cementation with different resin cements. Oper Dent 2013;38(5):555-564. DOI: 10.2341/11-494-L.

36. Bitter K, Paris S, Pfuertner C, et al. Morphological and bond strength evaluation of different resin cements to root dentin. Eur J Oral Sci 2009;117(3):326-333. DOI: 10.1111/j.1600-0722.2009.00623.x.

37. Giachetti L, Scaminaci Russo D, Baldini M, et al. Push-out strength of translucent fiber posts cemented using a dual-curing technique or a light-curing self-adhering material. Int Endod J 2011;45(3):249-256. DOI: 10.1111/j.1365-2591.2011.01969.x.

38. Goracci C, Corciolani G, Vichi A, et al. Light-transmitting ability of marketed fiber posts. J Dent Res 2008;87(12):1122-1126. DOI: $10.1177 / 154405910808701208$.

39. Radovic I, Corciolani G, Magni E, et al. Light transmission through fiber post: the effect on adhesion, elastic modulus and hardness of dual-cure resin cement. Dent Mater 2009;25(7):837-844. DOI: 10.1016/ j.dental.2009.01.004.

40. Fonseca RG, Cruz CA, Adabo GL. The influence of chemical activation on hardness of dual-curing resin cements. Braz Oral Res 2004;18(3):228-232. DOI: 10.1590/S1806-83242004000300009.

41. Ferrari M, Vichi A, Grandini S. Efficacy of different adhesive techniques on bonding to root canal walls: an SEM investigation. Dent Mater 2001;17(5):422-429. DOI: 10.1016/S0109-5641(00)00102-0.

42. Grandini S, Sapio S, Goracci C, et al. A one step procedure for luting glass fibre posts: an SEM evaluation. Int Endod J 2004;37(10):679-686. DOI: 10.1111/j.1365-2591.2004.00850.x.

43. Boing TF, Gomes $\mathrm{GM}$, Gomes JC, et al. Is the bonding of self-adhesive cement sensitive to root region and curing mode? J App Oral Sci 2017;25(1):2-9. DOI: 10.1590/1678-77572015-0430.

44. Sarkis-Onofre R, Skupien JA, Cenci MS, et al. The role of resin cement on bond strength of glass-fiber posts luted into root canals: a systematic review and meta-analysis of in vitro studies. Oper Dent 2014;39(1):E31-E44. DOI: 10.2341/13-070-LIT.

45. Daleprane B, Pereira CNB, Oréfice RL, et al. The effect of light-curing access and different resin cements on apical bond strength of fiber posts. Oper Dent 2014;39(2):E93-E100. DOI: 10.2341/12-477-L. 